\title{
The 1-Year Impact of Coronavirus Disease-19 Pandemic on Clinical Research and Publications
}

We have left 1 year behind since the coronavirus disease-19 (COVID-19) pandemic. Following the declaration of COVID-19 as a Public Health Emergency of International Concern on January 30, 2020, by the World Health Organization, all the balances and stabilities in the world have started to change. ${ }^{[1]}$ We now have a pandemic in our lives and it was inconceivable that it would affect everything. Inevitably, the quality and quantity of clinical trials and scientific research have also got their share. While clinical research and publications on COVID-19 are rapidly increasing, those in other fields are falling far behind.

In NCBI database on PubMed, there are more than 100,000 COVID-19-related papers between February 1, 2020 and February 1, 2021. ${ }^{[2]}$ According to Nature Journal analysis reported by Holly Else, between $17 \%$ and $30 \%$ of published articles were preprints depending on the database searched and one database around $4 \%$ of the world's research was focused on the COVID19 pandemic. Coronavirus papers were published much faster than normal and this at the expense of publishing research in other fields more slowly. ${ }^{[3-5]}$ There were also research publishing scandals which ended up in withdrawal or retraction of the papers. A case-control study done by searching PubMed database during the very early period of pandemic concluded that the quality of COVID-19 original articles in the three highest-ranked medical journals is below the average quality of these journals. ${ }^{[2,5]}$ The COVID-19 studies from the World Health Organization database are more than $3500{ }^{[6]}$ However, the answer to the question "what extent are the results of these studies provided for an accurate and effective treatment?" is also a matter of discussion.

The International Journal of the Cardiovascular Academy has published two papers related to COVID 19 pandemic within this period. Ekin and Ergene reported a $75 \%$ decrease in the number of primary percutaneous coronary intervention due to ST-elevation myocardial infarction (STEMI) and a $65 \%$ reduction of monthly average of STEMI cases ${ }^{[7]}$ and Gambaro et al..$^{[8]}$ discussed the connections between COVID-19 and low mortality rate in women.

Our journal has also been affected by the pandemic and we are able to include only five articles in this issue. This may be due to hard conditions of the health-care providers, including physicians and clinical scientists as well as our young colleagues at the beginning of their careers have to face. We hope that the negative impact of the pandemic on our daily social life as well as on our scientific activities subsides rapidly so that our journal again reaches the high submission rates prior to the pandemic and continues to contribute to cardiovascular knowledge with high-quality scientific work.

Mehdi Zoghi
Department of Cardiology, Faculty of Medicine, Ege University, İzmir, Turkey
ORCID:
Mehdi Zoghi: https://orcid.org/0000-0002-8156-2675

Address for correspondence: Dr. Mehdi Zoghi, Department of Cardiology, Faculty of Medicine, Ege University, İzmir, Turkey. E-mail:mehdi_zoghi@hotmail.com

\section{References}

1. WHO Timeline-COVID-19. Available from: https://www.who.int/news/ item/27-04-2020-who-timeline---covid-19. [Last accessed on $2020 \mathrm{Apr} 27$ ].

2. SARS-CoV-2 Data (NCBI). Available from: https://www.ncbi.nlm.nih. gov/sars-cov-2/. [Last accessed on 2021 Feb 18].

3. Aviv Reuven S, Rosenfeld A. Publication patterns 2 changes due to the COVID-19 pandemic: A longitudinal and short term scientometricanalysis. Available from: https://arxiv.org/abs/2010.02594. [Last accessed on $2021 \mathrm{Feb} 08$ ].

4. Holly Else. How a torrent of COVID science changed research publishing - In seven charts. Nature 2020;588:553. Available from: https:/www.nature.com/articles/d41586-020-03564-y.

5. Zdravkovic M, Berger-Estilita J, Zdravkovic B, Berger D. Scientific quality of COVID-19 and SARS CoV-2 publications in the highest impact medical journals during the early phase of the pandemic: A case control study. PLoS One 2020;15:e0241826.

6. COVID-19 Studies from the World Health Organization Database. Available from: https://clinicaltrials.gov/ct2/who_table. [Last accessed on 2021 Feb 15].

7. Ekin T, Ergene AO. Relationship between SARS-CoV-2 pandemic and ST-segment elevation myocardial infarction frequency. IJCA 2020;6:147-9.

8. Gambaro A, Xhyheri B, Rustamova Y, Caglar N. Female sex seems to be a favorable factor in COVID-19 era. IJCA 2020;6:143-6.

This is an open access journal, and articles are distributed under the terms of the Creative Commons Attribution-NonCommercial-ShareAlike 4.0 License, which allows others to remix, tweak, and build upon the work non-commercially, as long as appropriate credit is given and the new creations are licensed under the identical terms.

Received: 22-02-2021 Revised: 08-03-2021 Accepted: 10-03-2021 Published Online: 29-03-2021

\begin{tabular}{|l|l|}
\hline \multicolumn{2}{|c|}{ Access this article online } \\
\hline Quick Response Code: & Website: \\
& \\
& \\
&
\end{tabular}

How to cite this article: Zoghi M. The 1-Year impact of coronavirus disease-19 pandemic on clinical research and publications. Int J Cardiovasc Acad 2021;7:1. 